\title{
COMUNICAÇÃO NÃO VERBAL ENTRE MÃE E FILHO NA VIGÊNCIA DO HIV/AIDS À LUZ DA TACÊSICA ${ }^{a}$ \\ Non-verbal communication between mother and child in HIV/AIDS conditions from the perspective of the language of touch Comunicación no verbal entre madre e hijo con VIH/SIDA a la luz del tacésica
}

\author{
Marli Teresinha Gimeniz Galvão ${ }^{1}$ \\ Ênia Costa ${ }^{2}$ \\ Ivana Cristina Vieira de Lima ${ }^{3}$ \\ Simone de Sousa Paiva \\ Paulo César de Almeida ${ }^{5}$ \\ Lorita Marlena Freitag Pagliuca ${ }^{6}$
}

\section{RESUMO}

Propôs-se analisar a comunicação não verbal entre mãe e filho na vigência do HIV/AIDS à luz da tacêsica (linguagem do toque) durante o desempenho dos cuidados maternos. Estudo exploratório desenvolvido em ambiente experimental em Fortaleza-CE no segundo semestre de 2007 com cinco díades mãe-bebê. Foram utilizados três recursos para a coleta de dados: questionário semiestruturado sobre a história de vida da mãe e da criança; filmagens de cuidados maternos (troca, banho, ninar, brincar e alimentar); e roteiro de análise das filmagens baseado na tacêsica. Identificaram-se 354 interações, cujas análises apontaram que o banho apresentou maior número de interações mãe e filho, havendo ainda prevalência entre os cuidados do toque de intensidade firme e o uso do toque instrumental. Conclui-se que as relações mãe-filho inseridas no universo do HIV devem ser continuamente debatidas com vistas à promoção de cuidado mais eficaz, e que os cuidados maternos são uma oportunidade para fortalecer os laços afetivos mediante o uso do toque, promovendo o desenvolvimento emocional e social satisfatório da criança.
\end{abstract}

Palavras-chave: Comunicação. HIV-1. Relações Mãe-filho.

\begin{abstract}
This study aimed to analyze non-verbal communication between mother and child in HIV/Aids conditions by looking at the language of touch during the performance of maternal care. An exploratory research was developed in an experimental setting in Fortaleza-CE during the second semester of 2007, involving five mother-baby pairs. Three resources were used for data collection: semistructured questionnaire on the life history of mother and child; filming of maternal care (changing, bathing, lulling, playing and feeding) and a script to analyze the recordings based on the language of touch. The researchers identified 354 interactions, the analysis of which indicated that bathing presented the largest number of mother-child interactions, and that care with strong touch and the use of instrumental touch prevailed. It is concluded that the mother-child relations inserted in the HIV universe should be continuously debated with a view to more effective care promotion and that maternal care represents an opportunity to strengthen affective bonds by using touch, promoting the child's satisfactory emotional and social development.
\end{abstract}

Key words: Communication. HIV-1. Mother-Child Relations.

\section{Resumen}

Se propuso analizar la comunicación no verbal entre madre e hijo en la vigencia del VIH/Sida a la luz del Tacésica (lenguaje del tacto) durante el desempeño de los cuidados maternos. Estudio exploratorio desarrollado en ambiente experimental en Fortaleza-CE en el segundo semestre de 2007 con cinco díadas de madre-hijo. Fueron utilizados tres recursos para la colecta de datos: encuesta semiestructurada sobre la historia de vida de la madre y del niño; filmaciones de cuidados maternos (cambiar, bañar, acunar, jugar y alimentar) y guión de análisis de las filmaciones basado en del Tacésica. Se identificaron 354 interacciones, cuyas análisis apuntaron que el baño representó mayor número de interacciones madre e hijo, habiendo todavía prevalencia de los cuidados del toque de intensidad firme y el uso del toque instrumental. Se concluyó que las relaciones madre-hijo encuadradas incluídas en el universo del $\mathrm{VIH}$ deben ser continuamente debatidas con vistas a la promoción de cuidado más eficaz, y que los cuidados maternos son una oportunidad para fortalecer los lazos afectivos mediante el uso del toque, promoviendo el desarrollo emocional y social satisfactorio del niño.

Palabras claves: Comunicación. VIH-1. Relaciones MadreHijo.

'Enfermeira, Doutora, Professora do Departamento de Enfermagem e do Curso de Pós-Graduação em Enfermagem da Universidade Federal do Ceará. Email: marligalvao@gmail.com, ${ }^{2}$ Graduanda do Curso de Enfermagem da Universidade Federal do Ceará, Bolsista do CNPq, membro do grupo de Pesquisa Núcleo de Estudos em HIV/AIDS e Doenças Associadas. Brasil. E-mail: enia@bol.com.br, ${ }^{3}$ Graduanda do Curso de Enfermagem da Universidade Federal do Ceará, Bolsista do CNPq, membro do grupo de Pesquisa Núcleo de Estudos em HIV/AIDS e Doenças Associadas. Brasil. E-mail: ivanacristinalima@gmail.com, ${ }^{4}$ Enfermeira, Mestre em Enfermagem pela Universidade Federal do Ceará. Brasil. E-mail: simonecvc@yahoo.com.br, ${ }^{5}$ Estatístico, Professor da Universidade Estadual do Ceará (UECE). Brasil. E-mail: pc49almeida@gmail.com, ${ }^{6}$ Enfermeira. Doutora em Enfermagem. Professora Titular do Departamento de Enfermagem da UFC. Pesquisadora do CNPq. Brasil. E-mail: pagliuca@ufc.br 


\section{INTRODUCÃO}

A comunicação é um processo de interação no qual se compartilham mensagens, ideias, sentimentos e emoções possíveis de influenciar o comportamento das pessoas. Existem dois tipos de comunicação: a verbal e a não verbal. Enquanto a comunicação verbal exterioriza o ser social, a não verbal exterioriza o ser psicológico, e sua principal função é a demonstração dos sentimentos.

A comunicação não verbal envolve todas as manifestações de comportamento não expressas por palavras. Segundo se afirma, uma pessoa é influenciada pelo conteúdo verbal em $7 \%$, pelo tom de voz em $38 \%$ e pela expressão corporal em $55 \%$. $^{2}$ Quanto à forma, a comunicação não verbal se divide em: paralinguagem (modalidade da voz), proxêmica (uso do espaço pelo homem), tacêsica (linguagem do toque), características físicas (forma e aparência do corpo), fatores do meio ambiente (disposição dos objetos no espaço) e cinésica (linguagem do corpo). ${ }^{3}$

Em face das classificações, a tacêsica se relaciona ao toque, sua duração, local e tempo de contato, além de formas de aproximação. Por ser o tato um componente importante no modo como os bebês se consolam, exploram seu mundo e iniciam contato, ele é ativado antes do nascimento. ${ }^{4}$

De acordo com o revelado por determinados estudos, a relação da mãe com seu filho começa desde o período prénatal, por meio das suas expectativas sobre o concepto e da interação precoce estabelecida com ele, denominada vínculo. ${ }^{5}$ Alguns fatores podem alterar essa relação. Por exemplo, em virtude do HIV, a comunicação entre mãe e filho possui padrões diferenciados desde a gravidez, por causa do medo da transmissão do vírus, principalmente por essa situação perdurar até 0 estabelecimento do diagnóstico definitivo da criança, no segundo ano de vida, e também por causa da impossibilidade da amamentação ao seio. Aliado a isso, a mãe enfrenta o medo da morte da criança. Todas essas situações influenciam sobremodo a comunicação e o vínculo entre mãe e filho. ${ }^{6}$

Deste modo, em decorrência de os estudos acerca da comunicação não verbal, especificamente os relacionados à tacêsica, estarem direcionados à avaliação do toque durante interação enfermeiro-paciente, desenvolveu-se o presente artigo, motivado também pela lacuna de estudos relacionados ao cuidado materno na vigência do HIV/AIDS. 0 intuito é contribuir para proposições de cuidado às mães soropositivas e seus filhos mediante o estabelecimento precoce de uma comunicação efetiva para o fortalecimento das relações entre ambos.
Diante do exposto, este estudo tem por objetivo analisar a comunicação não verbal entre mãe e filho na vigência do HIV/ AIDS à luz da tacêsica durante o desempenho dos cuidados maternos em ambiente experimental.

\section{METODOLOGIA}

Trata-se de estudo do tipo descritivo e de abordagem quantitativa realizado no Laboratório de Comunicação da Saúde (LabCom_Saúde), localizado no Departamento de Enfermagem da Universidade Federal do Ceará.

Esse espaço é destinado a estudos experimentais na área de comunicação nos diversos contextos do cuidado em saúde. Em uma das suas distintas salas, a de filmagem, que possui isolamento térmico e acústico, foram distribuídas câmeras fixas ou móveis utilizadas de acordo com a necessidade. Esta sala é ligada a uma outra com equipamentos para armazenamento de imagem e som com vidro reflexo, onde o participante não vê o pesquisador, mas este observa todos os seus movimentos. Desenvolvida durante o terceiro trimestre de 2007, a investigação teve como sujeitos cinco binômios mãe-filho. Para a escolha, foram utilizados os seguintes critérios: mãe com diagnóstico de HIV/AIDS, com filho de até seis meses de idade, gerado na vigência da infecção materna. A seguir são descritas as etapas utilizadas no estudo.

1. A organização do ambiente experimental: $\mathrm{Na}$ sala principal do LabCom_Saúde foram montados ambientes assemelhados ao ambiente doméstico. Neles havia locais para o desenvolvimento de cuidado materno, tais como o banho, a troca de roupa do bebê, a oferta de alimento (mamadeira) e 0 brincar. Outro espaço foi planejado para confor tar a criança para ela dormir (niná-la). No primeiro espaço foi disponibilizada em uma bancada uma banheira contendo água em temperatura adequada. Na sequência havia outra bancada onde ficava um trocador, no qual a mãe podia proceder à troca de roupa do bebê. Sob as bancadas estavam dispostos: toalha, fralda de pano e descartável, sabonete, xampu, roupinhas, brinquedos, entre outros. Havia, ainda, um outro espaço onde ficavam uma poltrona confortável, mesa e brinquedos. Neste ambiente, a mãe podia oferecer o brinquedo (tipo chocalho), a mamadeira, além de acalentar o filho para niná-lo. 0 leite era preparado no laboratório, e para o oferecimento utilizava-se a mamadeira da criança. Como recomendado, utilizava-se a própria fórmula (leite em pó), tentando ao máximo evitar recusas da criança.

2. A captação de imagens: Foram utilizadas três câmeras de filmagem em pontos estratégicos para se evitar a interferência dos pesquisadores, todas dispostas em tripé a uma altura que possibilitasse a captação de imagens de ângulos apropriados do cuidado. Ao serem convidadas para o estudo, as 
Comunicação não verbal entre mãe e filho

mães escolheram um dia da semana mais conveniente para elas e, conforme combinado, permaneciam um período do dia no laboratório para realizarem todos os cuidados, de acordo com a rotina da criança. Não houve, porém, determinação de tempo para as mães desempenharem os cuidados, mas elas foram instruídas a agirem de modo semelhante ao usado no domicilio. Desta maneira, para cada binômio se obteve um tempo diferente de captação de imagens e, assim, o número de interações foi determinado pelo ritmo de cada mãe.

Em uma sala anexa, o pesquisador observava o cuidado materno através do vidro reflexo. Concomitantemente, também via pela tela de um computador as imagens captadas pelas câmeras e confirmava se a captação das cenas estava sendo adequada.

3. A busca de informações por meio de instrumentos: Foi adotado um formulário de avaliação e identificação da mãe e do filho que constava de dados socioeconômicos, demográficos e obstétricos. Estes dados eram informados antes do início das filmagens. Também foi utilizado um diário de campo no qual se anotavam outras situações ocorridas durante as filmagens.

Para a análise das interações maternas, elaborou-se um formulário utilizando-se parâmetros da literatura, relacionados à tacêsica, indicando-se os seguintes itens: intensidade do toque (leve e firme), tipos de toque (instrumental, expressivoafetivo, terapêutico, não intencional), frequência (1 vez, 2 vezes, 3 vezes, mais de 3 vezes) e velocidade da ação (rápida, moderada, lenta). ${ }^{2}$ Todas as cenas geradas foram gravadas em formato digital e deram origem a um DVD para cada binômio.

4. A avaliação das interações filmadas: Com vistas a esta etapa, houve a participação de dois peritos com conhecimento em comunicação, que receberam orientações prévias sobre a tacêsica. 0 tempo do cuidado materno variou entre os binômios, sendo que o tempo médio de filmagem foi de 35 minutos. Para a avaliação de cada cuidado, todos foram projetados em uma tela, e, a cada 30 segundos, a imagem era congelada e os juízes avaliavam e assinalavam os itens no roteiro de investigação. Das análises dos juízes foram obtidas 354 interações entre os cinco binômios.

Posteriormente, os dados foram processados pelo SPSS 14.0, e compararam-se as frequências absolutas e relativas entre as categorias das variáveis.

Como determinado, este estudo cumpriu todas as recomendações da resolução 196/96 sobre a investigação com seres humanos e foi aprovado pelo Comitê de Ética em Pesquisa da Universidade Federal do Ceará, sob protocolo 151/2007.

\section{RESULTADOS}

Para analisarmos os resultados, apresentamos breve informação dos binômios. A idade das mães variou entre $18 \mathrm{e}$ 34 anos, três delas eram donas-de-casa, e elas eram provenientes de segmentos pouco favorecidos da sociedade. Em quatro dos sujeitos em discussão, identificou-se sorodiscordância do parceiro em relação ao HIV. Três mães informaram que a gravidez dos filhos foi desejada. A idade dos bebês situou-se entre 39 e 153 dias de vida, e todos estavam em seguimento ambulatorial para redução das chances da transmissão do HIV. Todas as gestantes iniciaram o uso de tratamento com drogas específicas para redução da contaminação desde a gravidez.

De acordo com o exposto na Tabela I, o número de interações por binômio variou de 46 a 89, destacando-se 0 binômio 3 ( $n=89 ; 24,9 \%$ ). Nesse binômio percebeu-se mais interação da mãe com o bebê, e ela até utilizava muitas vocalizações para se comunicar com o filho. Em resposta, 0 bebê emitia sons guturais e movimentava as pernas em sinal de alegria.

Entre as formas de toque, o instrumental se constitui como o contato físico deliberado necessário para o desempenho de uma tarefa específica. ${ }^{2}$ Citam-se neste aspecto as atividades maternas de cuidado em relação à criança, manifestando-se diante da necessidade de esfregar a pele, pôr as fraldas e passar a pomada para prevenção de assaduras. 0 toque terapêutico demonstra uma tentativa da mãe em acalmar o bebê em face de uma reação inesperada dele, como o choro, o soluço e o espirro. Por sua vez, o toque não intencional, ou seja, aquele realizado de forma inconsciente e não premeditada é um achado pouco válido neste estudo, por não representar afeto e não se relacionar ao desempenho direto dos cuidados Como observado, a maioria das interações ocorreram mediante uso do toque instrumental $(77,6 \%)$, seguido pelo expressivoafetivo $(11,9 \%)$.

Entre os binômios, o banho foi o cuidado no qual as mães mais interagiram com os filhos ( $n=97 ; 27,2 \%$ ). Durante as interações, os toques de intensidade firme foram os mais frequentes ( $n=228 ; 64,3 \%$ ) (Tabela I). Conforme esta tabela, a velocidade das interações era, em maior porcentagem, moderada (44,8\%), e a frequência, de mais de três vezes a cada 30 segundos $(47,6 \%)$ das interações. 
Tabela I-Distribuição das 354 interações ocorridas entre os cinco binômios mãe-filho de acordo com a tacêsica em ambiente experimental, na vigência do HIV materno. Fortaleza-CE, 2007.

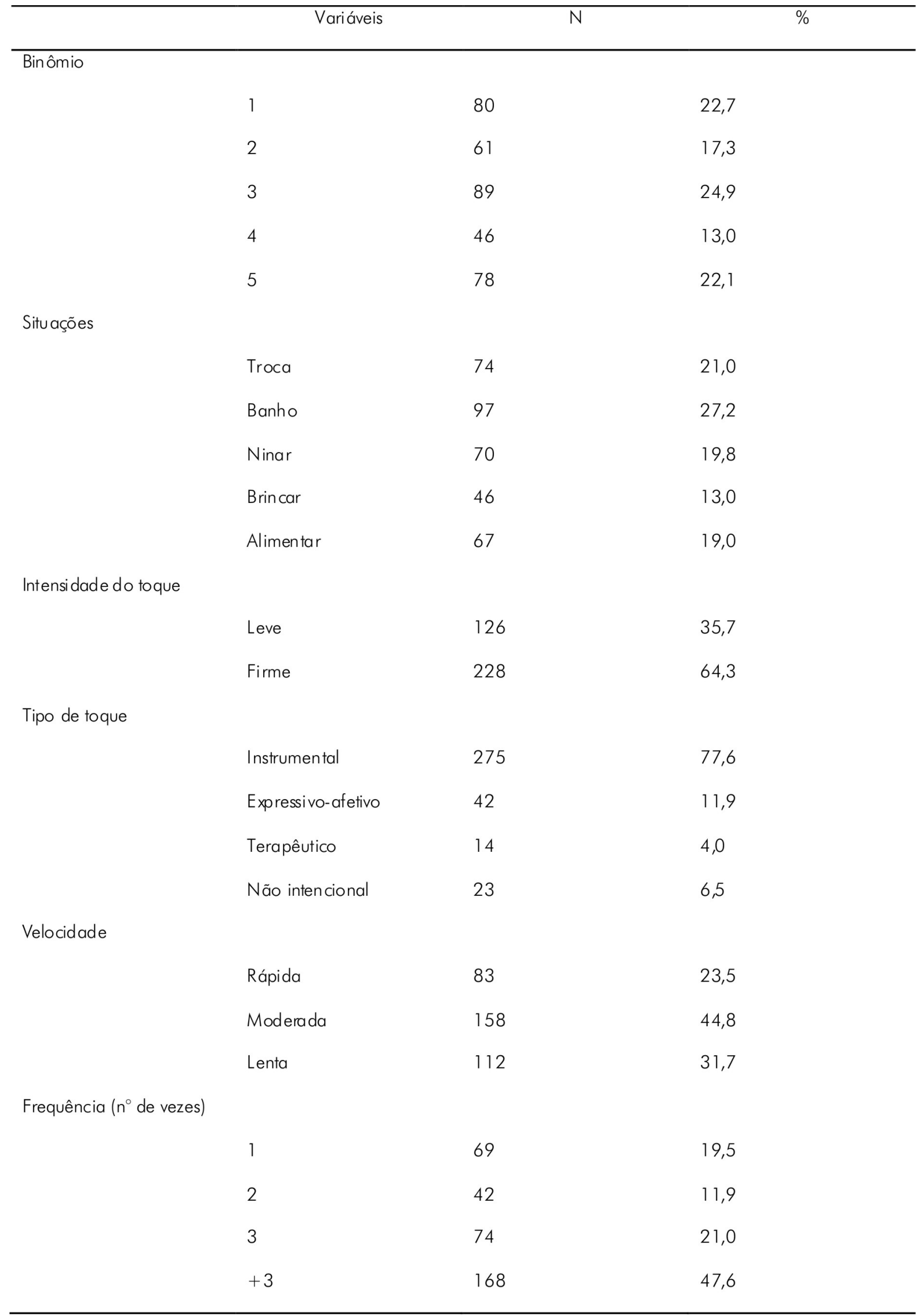




\section{DISCUSSÃO}

Como evidenciado ao se estudar o toque, seu componente fundamental é a transmissão da afetividade ao longo da interação mãe-filho. A mãe e a criança formam um sistema em virtude das interações, e, neste sistema, o comportamento de cada elemento é frequentemente estimulado pelo comportamento do outro. ${ }^{7}$ De acordo com a experiência, as crianças amamentadas ao seio desenvolvem vínculo mais forte com a mãe. Com base nesta afirmação, o HIV materno interfere na interação mãe-filho logo após o parto, em face da ausência do ato de amamentação. Esse processo, no contexto do HIV, é iniciado desde o diagnóstico do vírus para a mulher, por ser geralmente um período de sentimentos negativos, medo do preconceito e do abandono por parte do parceiro sexual e da sociedade, acarretando conflitos emocionais e psicológicos que se estendem até 0 momento da maternidade. ${ }^{8}$

Privadas da amamentação, as crianças filhas de mães com HIV podem encontrar no banho um momento de interação. Ademais, no banho o bebê revive momentos que the são familiares, pois permaneceu durante a gestação em contato com o meio líquido. Além disso, a constante necessidade de manipulação durante esse cuidado proporciona uma riqueza de interações. Portanto, a mãe deve aproveitar o momento para acariciar o bebê e permitir-lhe sentir pertencente a alguém. ${ }^{9}$ Contudo, como mostram os achados da presente investigação, o banho não foi um momento tão rico para a interação. Supõese que a banheira tenha produzido, em parte, uma espécie de barreira ou obstáculo entre a mãe e o bebê. Essa situação ocorria quando a mãe tinha apenas parte (tronco e cabeça) do bebê bem próximo a ela. Também, como percebido, havia "pressa" da mãe ao desenvolver esse cuidado com o filho (situação observada pelo pesquisador durante as filmagens).

Em relação ao ninar, a quebra da rotina diária e o fato de 0 cuidado ter sido realizado em ambiente experimental, com iluminação e ventilação artificiais, podem ter causado um sentimento de "estranhamento" nos bebês. Isto dificultou-hhes a obtenção de um sono mais profundo (observações do diário de campo). Além disso, em virtude de a mãe acalentar o bebê próximo ao corpo e pelos gestos deste como se quisesse encontrar algo no colo da mãe (alimento/mamas), também pode ter havido uma repulsa materna inconsciente motivada pelo temor da mãe diante da possibilidade de a criança procurar o seio materno.

No relacionamento infantil, o brincar se constitui um momento importante para o estabelecimento das interações entre mãe e filho, sobretudo por envolver trocas e influências mútuas e ambos interagirem em um contexto supostamente promotor do desenvolvimento emocional e de capacidades sociocognitivas. ${ }^{10}$ No entanto, segundo os resultados, o brincar não foi uma ação com muitas interaç̃̃es. Isso pode se justificar por três motivos simultaneamente interligados. Primeiro, por se desconhecer se a ação de brincar faz parte da rotina do cuidado destas mães. Segundo, por depender diretamente do estímulo materno, pois a cuidadora precisa ter a disposição para desenvolvê-lo. Terceiro, pelo sentimento das mães, pois, por estarem sendo indiretamente avaliadas, pode ter havido inibição do cuidado.

No tocante ao alimentar, os bebês sob risco da transmissão vertical do HIV estão impossibilitados de vivenciar um dos primeiros e essenciais prazeres biológicos: a sucção. Em consequência disso, "deixam" de compartilhar um momento único e integral de ligação com sua mãe. Conforme se percebeu, as cuidadoras procuraram expressar amor mediante outras formas de atenção, como carregar ao colo antes e durante a alimentação na mamadeira, manejar delicadamente a criança, olhá-la e acariciá-la.

A intensidade do toque é definida como a pressão usada sobre a superfície do corpo durante o toque e varia de acordo com a sensibilidade do local. ${ }^{2} 0$ toque firme foi observado em maior porcentagem. Este tipo de toque ocorre em virtude da constante necessidade da mãe de manipular a criança com firmeza para prover a sua sustentação, evitando quedas. No entanto, quando a mãe emprega muita força e velocidade e faz pressão sob o bebê, há uma repercussão negativa em relação à qualidade das interações. Esta categoria foi registrada em momentos específicos: ao colocar a criança na banheira, ao jogar água na cabeça da criança e ao realizar a troca de fraldas. ${ }^{11}$

Em face do HIV, a experiência da maternidade é afetada por fatores que incluem a possibilidade de cronicidade da doença da criança e a iminência da morte vivenciada pelas cuidadoras. Desse modo, pode despertar sentimentos controversos associados a culpa, angústia, ansiedade e superproteção.

Quanto às categorias de toque leve $(35,7 \%)$ e expressivoafetivo (11,9\%), remetem ao aconchego, à segurança e à proximidade/calor apresentados ao feto. Esse tipo de toque está presente nas interações maternas desde a vida intraútero, é apreciado pela criança e representa o "motor" do seu desenvolvimento físico, emocional, afetivo, social e intelectual. ${ }^{7} 12$ Pela expressão do amor, do carinho e dos laços verdadeiros, aumenta as chances de essa criança crescer mais saudável e ter uma vida de melhor qualidade, vencendo assim o desafio imposto desde o nascimento - a exposição ao HIV.13

Ao se analisar a velocidade com que o toque ocorre e associá-la à forma, pode haver situações de extremo carinho e delicadeza. Segundo descrito, os movimentos lentos acalmam a criança, funcionam como acalento. ${ }^{7}$ Nesta perspectiva, as mães do presente estudo desenvolveram pouco essa forma de alento.

0 toque rápido pode estar relacionado à pressa das mães na realização dos cuidados, apesar de terem sido orientadas quanto ao tempo livre para o desempenho das atividades. De acordo com a literatura, o território onde vivemos é o prolongamento de nós mesmos, marcado por signos visuais, 
vocais e olfativos. Assim, o ser humano organiza o espaço onde desenvolve seu cotidiano conforme sua própria personalidade. Desta maneira, estar em um local estranho exige uma reorientação espacial para adaptar-se ao novo ambiente. ${ }^{14}$

Em relação ao número de vezes em que a mãe tocou o filho, identificou-se a predominância da frequência de mais de três vezes. Como se pode supor, em decorrência de a mãe ter necessidade de manipular a criança para desempenhar os cuidados, amplia-se o número de vezes que se tocam. Tal situação é esperada no desenvolvimento do cuidado materno.

\section{CONSIDERAÇÕES FINAIS}

Este estudo envolvendo a avaliação de cuidados maternos na vigência do HIV demonstrou que, na comunicação não verbal, mediante a tacêsica, o toque é um componente importante no modo e nas interações entre mãe e filho, pois esteve presente em todos os cuidados. Contudo, é mais comum nas interações mãe-criança nos primeiros meses de vida.

Ainda, conforme se pôde compreender pela tacêsica, o ato de tocar transcende sua obrigatoriedade para a realização do cuidar. No estudo, predominou o toque de intensidade firme, indicando a necessidade de a mãe utilizá-lo para a proteção da criança, evitando risco de acidentes.

\section{REFERÊNCIAS}

1.Stefanelli M. Comunicação com paciente: teoria e ensino. São Paulo (SP): Ed. Robe; 1993.

2.Silva MJP. Comunicação tem remédio: a comunicação nas relações interpessoais em saúde. São Paulo (SP) Ed Loyola; 2006.

3.Knapp ML. La comunicación no verbal: el cuerpo y el retorno. Barcelona(ES): Paidós; 1980.

4.Cruz DCS, Sumam NS, Spíndola T. Os cuidados imediatos prestados ao recém-nascido e a promoção do vínculo mãe-bebê. Rev Esc Enferm USP [serial on the Internet]. $2007 \mathrm{dez}$ [citado 13 julho 2008]; 41(4): [aprox 8 telas.]. Disponível em: http://www.scielo.br/scielo.php.

5. Piccinini CA, Gomes AG, Moreira LE et al. Expectativas e sentimentos da gestante em relação ao seu bebê. Psicol Teor Pesq 2004; 20(3): 223-32.

6. Vasconcelos SG, Galvão MTG, Aguiar MIF, Braga VAB. A percepção das gestantes ao lidar com a infecção pelo HIV: estudo exploratório. Online Braz J Nurs [periódico na internet] 2006; 5(1). [citado 17 jul 2008]. Disponível em: http://www.uff.br/objnursing/index.php/nursing/ article/view/61/19

7.Molcho S. A linguagem corporal da criança. São Paulo(SP): Gente; 2007.
Como mostra a literatura, pesquisas utilizando esse componente da comunicação entre mãe e filho são raras. De igual modo, o uso de filmagem em ambiente experimental constitui um modo recente de avaliação nos cenários mais comuns do cuidado materno. Apesar disso, a investigação ora desenvolvida possibilitou um olhar inovador sobre a interação mãe-filho e proporcionou uma nova maneira de avaliar a relação entre o binômio, na vigência do HIV. Tais avaliações propiciaram auxiliar na compreensão precoce de como a tacêsica se apresentou nos cuidados maternos.

Por sua vez, o ambiente experimental pode ter influenciado o comportamento dos sujeitos da pesquisa, pois se apresenta distinto do ambiente domiciliar, sugerindo assim que estudos futuros sejam aplicados em ambiente natural.

Conclui-se que as relações mãe-filho inseridas no universo do HIV devem ser debatidas com vistas à promoção de cuidado mais eficaz a essa clientela, situações pouco divulgadas em nossa sociedade. É papel do profissional que assiste essas mães incentivá-las a transformar os momentos dos cuidados maternos em uma oportunidade para o for talecimento dos laços afetivos por meio do uso do toque, promovendo o satisfatório desenvolvimento emocional e social da criança.

8.Araújo MAL, Silveira CB. Vivências de mulheres com diagnóstico de Doença Sexualmente Transmissível - DST. Esc Anna Nery Rev Enferm 2007; 11(3): 479-86.

9.Ferreira EA, Vargas IMA, Rocha SMM. A bibliographical study on the mother and son attachment: bases for the pediatric and neonatal nursing care. Rev Latino-am Enfermagem 1998; 6(4): 111-16.

10.Mendes DMLF, Moura MLS. Desenvolvimento da brincadeira e linguagem em bebês de 20 meses. Psicol Teor Pesq 2004; 20(3): 215-22.

11.Silva SSC, Le Pendu Y, Pontes FAR et al. Sensibilidade materna durante o banho. Psicol Teor Pesq 2002; 18 (3): 345-52.

12.Rappaport CR. A infância inicial: o bebê e sua mãe. São Paulo (SP): EPU; 2003.

13.Paula CC, Crossetti MGO. 0 modo de cuidar no encontro com o ser-criança que convive com AIDS: o experienciar da finitude e da ética. Texto\& Contexto Enferm 2004; 14(02): 193-201.

14. Hall ET. A dimensão oculta. Lisboa (PO): Relógio d'água; 1986. NOTA

aEstudo desenvolvido com recursos institucionais do CNPq 